\title{
Por que ir à Escola? Os sentidos atribuídos pelos jovens do ensino médio
}

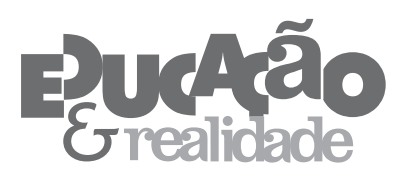

Beatriz Prado Pereira' Roseli Esquerdo Lopes"

'Universidade Federal da Paraíba (UFPB), João Pessoa/PB - Brasil "Universidade Federal de São Carlos (UFSCar), São Carlos/SP - Brasil

RESUMO - Por que ir à Escola? Os sentidos atribuídos pelos jovens do ensino médio. O objetivo da pesquisa da qual decorre este texto foi analisar os sentidos que a escola tem para jovens no último ano do Ensino Médio regular, na tentativa de compreender as peculiaridades e os significados de sua permanência na Educação Básica. Para tanto, em 2013, em São Carlos (SP), foi aplicado um questionário junto aos alunos de escolas públicas e particulares da cidade. Posteriormente, com um grupo desses estudantes, foram realizados encontros denominados conversa coletiva, com vistas a produzir uma reflexão a partir dos resultados obtidos com os questionários. Ao se posicionarem, os jovens compõem sentidos positivos e se motivam em relação à escola, não obstante, apontam deficiências nela presentes sem, com isso, desvalorizá-la.

Palavras-chave: Escola. Ensino Médio. Juventudes. Sentidos da Escola.

ABSTRACT - Why go to School? The meanings assigned by Secondary Education students. This paper results from a research aimed at analyzing the meanings assigned by Secondary Education senior year students to school, in an attempt to understand the peculiarities and purposes of their permanence in Basic Education. To this end, a questionnaire was filled in by students of public and private schools in 2013 in São Carlos, São Paulo (Brazil). Afterwards, meetings entitled as collective talks were performed with one group of these students in order to produce a reflection based on the results gathered from the questionnaires. When giving their opinion, the students revealed positive meanings and motivated attitudes towards the school. Nevertheless, they pointed out the shortcomings of school without diminishing its value.

Keywords: School. Secondary Education. Youth. School Meanings.

Educação \& Realidade, Porto Alegre, v. 41, n. 1, p. 193-216, jan./mar. 2016. 


\section{Introdução}

A contemporaneidade é marcada por um contexto de transitoriedade e descontinuidade nos mais diversos sentidos. O mercado se modifica intensa e continuamente, formatando a consequente falta de perspectiva de compromissos duradouros e enfatizando o curto pra$z o$, o que influencia as relações de trabalho e interfere na criação e no aprofundamento dos laços sociais, explicitando crescentes conflitos em nosso cotidiano. As relações pessoais, intrapessoais e interpessoais, que se sustentam com uma construção a longo prazo, não mais ganham uma concretude que se sustente diante da tendência à liquefação das condições básicas para o estabelecimento de experiências compartilhadas (Sennett, 2009).

Para Bauman (2001), a modernidade se reveste de um aparato calcado numa versão privativa e individualizada das relações sociais; por meio do conceito de modernidade líquida, busca caracterizá-las, uma liquidez que impediria a captação do real, de um concreto que ganha múltiplos contornos por sua grande capacidade de fluir e de moldar-se. Fluidez, maleabilidade, flexibilidade e a potencialidade de moldar-se em relação às infinitas estruturas são algumas das características que o estado liquefeito da atual conjuntura conferirá às tantas esferas dos relacionamentos humanos. Na modernidade líquida, há menos compromisso com a ideia de permanência e durabilidade, os tempos são líquidos, pois tudo muda de maneira acelerada (Bauman, 2001).

Seriam sintomas ou sinais dessa perspectiva a incerteza na vida cotidiana, a insegurança na cidade, a fragilidade dos laços afetivos e do trabalho, o desprendimento das redes de pertencimento social, a substituição do que é constante, a diversidade de escolhas, o excesso de informações, as disformes relações familiares e amorosas e a desestruturação do emprego.

Os jovens sentem a vida marcada por crescentes inconstâncias, flutuações, descontinuidades e reversibilidade, vivendo em uma modernidade labirinto, termo que, para José Machado Pais (2005), explicitaria a complexidade e o caos da sociedade em que vivemos. Estruturas sociais crescentemente labirínticas levam os jovens contemporâneos a ficarem mais propensos a vivências que caracterizam as trajetórias ioiô (Pais, 2005), uma analogia apropriada do brinquedo que sobe e desce, vai e vem, e caracteriza um aspecto essencial das culturas juvenis atuais que resultam de situações díspares. Ora são rígidas e uniformes, ora são flexíveis e opcionais.

Essa geração ioiô (Pais, 2005) é dominada pelo aleatório e parece viver a lógica da experimentação, que possibilita essa movimentação em relação a profissão, estudos, relacionamentos e compromissos. Nessa lógica, os jovens desenvolvem a tendência a relativizar as diferentes estruturas que os constituem social e individualmente, já que, como 
exemplo, o diploma não necessariamente garante trabalho, dentro da inconstância do próprio mercado de trabalho. Muitas vezes, saem da casa dos pais e voltam, abandonam os estudos depois retornam, conseguem um emprego e depois o perdem, as voltas e mais voltas nas relações amorosas, o estilo de vida escapatório, tudo isso garante, ilustra e acentua a mobilidade e plasticidade da sociedade com seus movimentos oscilatórios e reversíveis (Pais, 2005).

É preciso entender e refletir sobre a sociedade em que o jovem está inserido e na qual ele experimenta, circula e compartilha afetos. Também é preciso reconhecer que ele organiza essas trocas segundo uma coerência que persegue os sentidos estabelecidos nessa e por essa sociedade. Independentemente da discussão em torno do que seja(m) a(as) juventude(s) $)^{1}$, é importante compreendê-la(s) como um grupo social que possui especificidades e que é influenciada pelo meio e modo histórico/social em que se desenvolve, pela qualidade das trocas que proporciona.

A partir da segunda metade do século XX, começaram a surgir novas concepções do termo juventude, que contribuíram para os debates, instaurando posicionamentos ora contrários, ora complementares acerca das compreensões formadas. Essa ambiguidade é apresentada por Iulianelli (2003), quando situa, de um lado, a juventude vista como agente de transformação social e, de outro, como uma parcela social marcada pela ingenuidade e irracionalidade.

Dentro da diversidade de ideias e reflexões acerca da noção de juventude, para muitos ela se estabelece como uma simples fase da vida, em algumas situações é associada a um período de otimismo e descoberta, além de ser uma força social renovadora. Para outros, por vezes, torna-se sinônimo de um tempo de irresponsabilidade e dependência, de rebeldia e até de delinquência, a depender da classe socioeconômica na qual o jovem se encontra (Schwertner; Fischer, 2012).

Assim, deparamo-nos cotidianamente com essas séries de imagens, pré-conceituações e estereótipos a respeito da juventude e, queiramos ou não, elas interferem na maneira como a vemos e compreendemos. Uma das mais tradicionais representações para a faixa etária ${ }^{2}$ (o que também integra o debate ${ }^{3}$ ) é a sua condição de transitoriedade, de passagem para a vida adulta, na qual o jovem é um vir a ser, tendo no futuro o sentido de suas ações no presente. Sob essa perspectiva, há uma tendência de encarar a juventude em sua negatividade, como algo que ainda não chegou a ser, negando-se muitas vezes o presente vivido (Dayrell, 2007).

Um dos traços que mais caracteriza a atual condição juvenil é a situação de impasse experimentada por muitos jovens em relação ao futuro, uma vez que o caminho para a vida adulta é pouco claro, em suas possíveis escolhas e indeterminações. Apesar de as fronteiras entre as várias fases da vida se encontrarem sujeitas a crescentes hesitações, 
continuam a ser valorizados alguns determinados marcadores de passagem para sua fase adulta, havendo um reconhecimento genérico, por exemplo, quanto a idades mínimas para ter relações sexuais, deixar a escola, casar, ter filhos e iniciar uma carreira profissional (Pais, 2009).

É fato que as implicações no entendimento de que esse grupo populacional constrói determinados modos de existir distanciam-nos do discurso de que possa haver um único modo de ser e categorizar o jovem. É nesse sentido que se tem a noção de juventudes, no plural, para destacar a diversidade de situações existentes nos modos de ser jovem (Dayrell, 2003).

Além disso, o jovem deve ser considerado como sujeito, “[...] um ser humano levado pelo desejo e aberto para um mundo social no qual ele ocupa uma posição e do qual é elemento ativo" (Charlot, 2000, p. 57), que é portador de desejos e é movido por eles. Ao mesmo tempo, o sujeito é um ser social, com uma determinada origem familiar, que ocupa um determinado lugar na estrutura das relações sociais em que está inserido. Dessa forma, considera-se o sujeito como um ser singular, que tem uma história, que interpreta o mundo e lhe atribui sentido, bem como dá sentido à posição que ocupa nele, às suas relações com os outros, à sua própria história e à sua singularidade. O sujeito é ativo, age no e sobre o mundo, e nessa ação se produz e, ao mesmo tempo, é produzido no conjunto das relações sociais em que se insere (Dayrell, 2003).

O debate acerca das compreensões sobre a juventude é de extrema importância, pois delas decorrem determinados tipos de ações direcionadas a essa população. Há, portanto, como exemplo, um rebatimento entre o conceito e a formulação no campo das políticas. Em outras palavras, a partir de suas conceituações, serão retratadas e interpretadas formas de ser e estar no mundo e, também, como a sociedade se organiza na atenção a essas fases da vida, especialmente na maneira como são configurados os direitos e os deveres dos adolescentes e dos jovens e quais são as ações sociais e políticas reivindicadas (Lopes et al., 2008).

As políticas para essa população, no Brasil, a par da centralidade das proposições educacionais escolares, geralmente são programas de formação profissional e de oferecimento de serviços especiais de saúde, cultura e lazer. Nas instituições que se voltam aos trabalhos sociais, como algumas organizações não governamentais (ONGs), as ações tendem a desenvolver projetos destinados a jovens e adolescentes em situação de risco e desvantagem social, visando diminuir as dificuldades de integração social (Abramo, 1997).

Conforme Abramo (1997), esse contexto é gerado pela sensação de urgência frente a situações de desamparo, desregramento e que, todavia, tem permanecido num apontamento muito imediatista e desarticulado das ações; ela ressalta, igualmente, a pouca capacidade de se produzir uma compreensão mais ampla e aprofundada a respeito do público-alvo, de suas características (suas questões e modos de expe- 
rimentar e interpretar essas situações problemáticas), consolidando-o naquele contexto. Existem propostas centradas na noção de que os jovens são colaboradores e partícipes nos processos educativos, as quais, tomando uma perspectiva de protagonismo juvenil, buscam com eles se desenvolverem; não obstante, a grande maioria daqueles trabalhos se limita ao enquadramento anterior (Abramo, 1997).

Para alguns autores, os estudos sobre as juventudes relatam a acentuada participação dos jovens na escola, no trabalho, na família, nas instituições e nos movimentos sociais, dando ênfase para a questão do protagonismo juvenil, com isso, ressaltam a importância de depositar "[...] um olhar sobre os jovens como atores e não como simples reprodutores daquilo que vivenciam e experimentam" (Schwertner; Fischer, 2012, p. 399-400). Nessa apreensão, o foco está no que o próprio termo protagonismo representaria quanto a pensar o jovem como ator principal, como criador e agente de transformação das formas de vida nos diversos ambientes pelos quais circula e age. Por esse motivo, torna-se essencial compreender como os aspectos oriundos destes tempos de globalização, como o individualismo, o consumismo, as diversas formas de desigualdades e de estreitamento de tempo e espaço, vêm impactando os jovens e como estes estariam produzindo formas de enfrentamento e alternativas.

Entendemos a juventude como parte de um processo mais amplo de constituição de sujeitos, mas que tem especificidades que marcam a vida de cada um. Trata-se de um período determinado, porém não se reduz a uma passagem; ela assume uma importância em si mesma, "[...] todo esse processo é influenciado pelo meio social concreto no qual se desenvolve e pela qualidade das trocas que este proporciona" (Dayrell, 2003, p. 14).

No Brasil do século XXI, ao se relacionar escola e juventude, ainda são grandes as lacunas no que diz respeito à equidade e qualidade, pois é no âmbito dessa instituição que a maior parte dos jovens toma consciência de oportunidades e possibilidades existentes, mas é onde, ao mesmo tempo, tem a percepção de que lhes são negadas as condições reais para aproveitá-las. As experiências escolares dos jovens, muitas vezes, evidenciam que a instituição escolar se coloca distante de seus interesses e necessidades, não conseguindo entender nem responder suas reais demandas, pouco contribuindo em suas construções como sujeitos (Dayrell, 2007).

É possível notar em textos, estudos, discussões, nas construções das leis e das diretrizes sobre a educação brasileira o quanto é nítida uma dualidade estrutural que se expressa numa fragmentação da escola. Delineiam-se caminhos diferenciados segundo a classe social do aluno; de um lado, o caráter de formação geral humanista dirigido à elite; de outro, o profissionalizante destinado à população mais pobre (Kuenzer, 2005).

Educação \& Realidade, Porto Alegre, v. 41, n. 1, p. 193-216, jan./mar. 2016. 
Por que ir à Escola?

Essa dualidade, bastante acentuada no Ensino Médio, tem base na difícil tarefa de estruturação por ele requerida. Apesar de sua importância, continua a persistir a falta de definição de seu estatuto pedagógico, ou seja, não se tem clareza sobre a função educacional dessa fase escolar. É ela propedêutica ao Ensino Superior? É profissionalizante ou pré-profissionalizante? (Nosella, 2011).

O impasse, a indecisão e o não esclarecimento sobre a função elementar desse nível de ensino são verificados nas contínuas interpretações teóricas e nas formulações das legislações criadas especificamente. Destacam-se, ainda nas atuais proposições, a tendência ao seu caráter dualista e a dúvida quanto ao Ensino Médio ser uma etapa conclusiva da Educação Básica ou uma etapa intermediária e preparatória para continuidade dos estudos técnicos/profissionais ou universitários.

Essa característica dual foi estabelecida historicamente, desde os primórdios da educação no Brasil. Na história do desenvolvimento humano em suas relaçõ̃es com o mundo produtivo, foi persistente a existência de um dilema entre trabalho manual e trabalho intelectual, mundo da escola e mundo do trabalho, além da dualidade entre a arte do fazer e a arte do pensar (Frigotto, 1989).

A indecisão sobre a função do Ensino Médio, recorrente entre nós, por estar sempre interligada com as mudanças e dimensões políticas, econômicas, culturais e sociais do momento em que se propõe uma construção curricular para esse nível de ensino, não é uma questão apenas pedagógica, é também política, determinada pelas mudanças nas bases materiais de produção, é concordante com a história e do que nela se define sobre as relações entre trabalho e educação (Kuenzer, 2007).

Nesse contexto, quando relacionamos jovens e escola, observa-se que muitos deles acabam evadindo dessas instituições e sofrendo as consequências da falta de uma formação escolar. Situação que é em parte determinada por fatores como a falta de interesse, a violência, os maus-tratos, a indisciplina e a ausência de incentivos relacionados aos estudos (Lopes et al., 2008; Lopes et al., 2011; Lopes et al., 2012). Apesar disso, existem aqueles que permanecem na escola, satisfeitos ou não, com dificuldades ou não. A pesquisa da qual decorre este artigo foi uma tentativa de compreender as peculiaridades e os sentidos dessa permanência.

\section{Procedimentos Metodológicos}

O estudo foi desenvolvido na cidade de São Carlos, localizada na região central do estado de São Paulo, com uma população estimada em 236.457 habitantes, dos quais $96 \%$ residem na área urbana, conforme os dados do Instituto Brasileiro de Geografia e Estatística (IBGE) de 2013. A população jovem do município, entre 15 e 29 anos, consiste em 56.893 habitantes, representando $25,63 \%$ do total de indivíduos (IBGE, 2013). 
Em relação às escolas, o levantamento contabilizou 33 escolas com Ensino Médio regular, sendo 19 públicas e 14 particulares, com um total de 2.370 alunos matriculados no último ano do Ensino Médio em 2013. A escolha por focalizar os alunos do último ano do Ensino Médio se deu pela tentativa de abarcar aqueles que passaram por toda a Educação Básica e estavam para finalizá-la. Dada essa escolha, não nos voltamos para os alunos das modalidades Educação de Jovens e Adultos (EJA) e profissionalizante, tendo em vista que é no Ensino Médio regular que se encontra a maior parte dos jovens brasileiros (Brasil, 2015).

Decidiu-se por estudar escolas de regiões e naturezas institucionais distintas com o intuito de abranger jovens com percursos e situações socioeconômicas diferentes, a fim de garantir que o conjunto de informantes fosse diversificado e, assim, reunir múltiplas realidades, possibilitando a apreensão de semelhanças e divergências entre uma geração presente nas escolas.

A coleta de dados ocorreu em dois momentos, com procedimentos diferentes.

Em uma primeira etapa, optou-se pela aplicação de um questionário estruturado com perguntas fechadas que demandavam respostas objetivas com a finalidade de propiciar aos alunos possíveis reflexões sobre os sentidos e significados da escola em suas vidas. A escolha por esse instrumento deveu-se à intenção de se obter um retrato da visão dos jovens da cidade, abarcando o universo como um todo, buscando tornar visível alguns conjuntos de problemáticas que, muitas vezes, permanecem desconhecidas e poderiam ser objeto de novas investigações dentro de uma abordagem compreensiva.

Tomando-se nossas experiências e interações com jovens, bem como a revisão de outros trabalhos, percebemos que suas respostas e seus posicionamentos imediatos, quando questionados sobre a função da escola, são muito semelhantes e refletem o que é esperado socialmente, evidenciando o consenso sobre a escola como um local para a conquista de um bom trabalho e/ou para a entrada no Ensino Superior.

Entretanto, na tentativa de captar outros sentidos que os jovens pudessem dar para a escola, sentidos mais pessoais, que geralmente são pouco mencionados, refletidos e considerados, para a formulação do questionário, foram elencadas respostas pelas quais os jovens poderiam optar, colocadas como alternativas, tendo a possibilidade de refletir sobre cada item e assinalar ou não outros prováveis sentidos e significados da instituição escolar em suas trajetórias ${ }^{4}$.

Esses dados foram tratados pela estatística descritiva, caracterizando os indivíduos do estudo. Para as variáveis qualitativas as estatísticas apresentadas foram as frequências absolutas (n) e as frequências relativas (\%). Para as variáveis quantitativas, como medidas resumos: a média e a mediana e para apontar a variabilidade, o desvio-padrão, mínimo e máximo (Magalhães; Lima, 2000). 
Em um segundo momento, trabalhou-se com cinco jovens que responderam ao questionário inicial e se disponibilizaram a continuar e colaborar com a pesquisa. Foram listados vinte estudantes e, aleatoriamente, passamos a convidar alunos e alunas de escolas diferentes em relação às regiões da cidade, públicas e privadas, para a participação de uma conversa em profundidade ${ }^{5}$, a partir de uma vertente que autoriza a compreensão, de maneira coletiva, da percepção acerca dos sentidos que a escola tem, de como a educação formal se constitui para os alunos e da possibilidade de dialogar e refletir juntos sobre os resultados dos questionários realizados anteriormente.

Chamados de conversa coletiva, esses encontros tinham a intenção de criar oportunidades e espaços de diálogo, no qual os colaboradores pudessem se expressar e, sobretudo, escutar os outros e a si mesmos, por meio de trocas de experiências, conversas e discussões que estimulariam a problematização e trariam à tona como cada sujeito percebe e significa a sua realidade.

Os encontros geraram uma conversa bastante intensa pela diversidade de opiniões e experiências vividas fora e dentro da escola. Quatro jovens de escolas públicas e uma jovem de escola particular constituíram-se como um grupo crítico e ciente sobre a situação da escola e da educação atual, independentemente das conclusões e conceituações de cada um, as faíscas de esperança em relação às mesmas instituições iluminaram o debate de diversas formas. Em comum, o depósito de boas perspectivas e expectativas para o futuro de que tratamos, com depoimentos que se intercalavam entre o otimismo e o pessimismo, o ânimo e o desânimo e as contrariedades vivenciadas dentro dos contextos escolares.

A seguir, apresentamos uma síntese dos resultados que conseguimos produzir com esse material coletado no primeiro e segundo semestres de 2013. No início do primeiro semestre de 2014, esses resultados foram igualmente apresentados às direções das escolas que concordaram em participar e discutidos com aquelas que se disponibilizaram.

\section{Caracterização Geral dos Jovens Participantes}

Foram 861 alunos que responderam ao questionário, no início do ano de 2013; de 33 escolas (19 públicas e 14 particulares), concordaram em colaborar com a pesquisa 13 públicas e 6 particulares. Do total de respondentes desses questionários, $22 \%$ eram de escolas particulares e $78 \%$ das escolas públicas. Ainda, $44 \%$ eram garotos e $56 \%$ garotas.

Em relação à idade dos jovens no momento da pesquisa, a maioria (59,9\%) tinha 17 anos ${ }^{6}$. O mínimo e o máximo das idades observadas foram 15 e 20 anos, respectivamente. Podemos, portanto, afirmar que os alunos acessados estavam na idade considerada ideal para o último ano da Educação Básica, pois sua maior parte concluirá o terceiro ano entre 17 e 18 anos. 
O período da manhã foi o de maior frequência entre os alunos das escolas participantes, com 81,4\% (701 alunos), seguido do noturno com $18,6 \%$ (160 alunos) estudantes. Das seis escolas particulares estudadas, todas as suas sete turmas eram matutinas, enquanto nas 13 escolas públicas, nove turmas eram noturnas e 21 matutinas.

Os jovens alunos que responderam ao questionário são aqueles que chegaram ao último ano da Educação Básica e estão para finalizá-la. Tal recorte possibilitou o estabelecimento de certa homogeneização, porém existem singularidades e diversidades em relação a idades, gêneros, tipos de escola e período em que estudavam, além de questões subjetivas que interferiam nas opiniões sobre os sentidos que davam ou não à escola.

\section{Por que ir à Escola? o que nos dizem jovens no final do ensino médio}

A educação anda e sempre andou atrelada às transformações sociais, culturais, históricas, econômicas e políticas do país, ou seja, entender o sentido que a escola ocupa na vida dos jovens significa entender que eles estão dentro de uma instituição, inclusos e pertencentes a uma sociedade, que está inserida em um sistema com uma estrutura social estabelecida por interconexões e interferências, o qual influencia os processos educacionais desses jovens e os sentidos e significados atribuídos à escola por eles.

A representatividade e abrangência dos dados numéricos, junto à conversa coletiva com os próprios alunos sobre os resultados dos questionários que eles e seus colegas responderam, colocam os jovens estudantes como interlocutores válidos e privilegiados para a compreensão do Ensino Médio, tratando-os como autores principais que vivenciam, conhecem e, por conta disso, avaliam e criticam a educação que lhes é oferecida. Com isso, é preciso considerar suas críticas fundamentadas e interpretá-las como uma forma de contribuição para a melhoria das escolas e da educação.

Na Figura 1, a seguir, são apresentados os percentuais de alunos que assinalaram sim ou não aos itens elencados como possibilidades para os sentidos do ir para a escola. 
Por que ir à Escola?

Figura 1 - Percentuais de respostas com relação aos motivos pelos quais vão à escola para estudantes do último ano de Ensino Médio em São Carlos/SP, 2013

\begin{tabular}{|l|c|c|}
\hline Possibilidades & Não & Sim \\
\hline Você vai para escola porque é obrigado? & $84,9 \%$ & $15,1 \%$ \\
\hline $\begin{array}{l}\text { Você vai à escola porque há alguma relação com os seus } \\
\text { valores (sociais, pessoais, familiares, religiosos)? }\end{array}$ & $2,1 \%$ & $97,9 \%$ \\
\hline Você vai à escola porque é seu direito? & $15,3 \%$ & $84,7 \%$ \\
\hline Você vai à escola porque gosta de aprender? & $9,1 \%$ & $90,9 \%$ \\
\hline Você vai à escola porque se interessa por alguma disciplina? & $20,6 \%$ & $79,4 \%$ \\
\hline Você vai à escola porque gosta dos professores? & $55,8 \%$ & $44,2 \%$ \\
\hline $\begin{array}{l}\text { Você vai à escola porque acha importante para conseguir um } \\
\text { trabalho futuramente? }\end{array}$ & $2,7 \%$ & $97,3 \%$ \\
\hline $\begin{array}{l}\text { Você vai à escola para tentar entrar na faculdade/ensino } \\
\text { superior? }\end{array}$ & $6,2 \%$ & $93,8 \%$ \\
\hline $\begin{array}{l}\text { Você vai à escola para ter melhores condições de vida do que a } \\
\text { dos seus pais/ responsáveis? }\end{array}$ & $11,2 \%$ & $88,8 \%$ \\
\hline Você vai à escola para fazer amigos? & $27,4 \%$ & $72,6 \%$ \\
\hline Você vai à escola porque seus amigos vão? & $72,8 \%$ & $27,2 \%$ \\
\hline Você vai à escola para paquerar? & $83,3 \%$ & $16,7 \%$ \\
\hline Você vai à escola para encontrar seu/sua namorado/a? & $92,8 \%$ & $7,2 \%$ \\
\hline Você vai à escola para se divertir? Como uma forma de lazer? & $70,0 \%$ & $30,0 \%$ \\
\hline Você vai à escola porque gosta do intervalo? & $80,7 \%$ & $19,3 \%$ \\
\hline Você vai à escola por causa da merenda? & $94,8 \%$ & $5,2 \%$ \\
\hline
\end{tabular}

Na Figura 2, podemos verificar algumas perguntas disponibilizadas no questionário e as porcentagens relativas às respostas referentes aos itens mais frequentes, dentre as principais razões para os jovens irem à escola.

Figura 2 - Razões apontadas pelos jovens sobre os motivos pelos quais vão à escola ${ }^{7}$

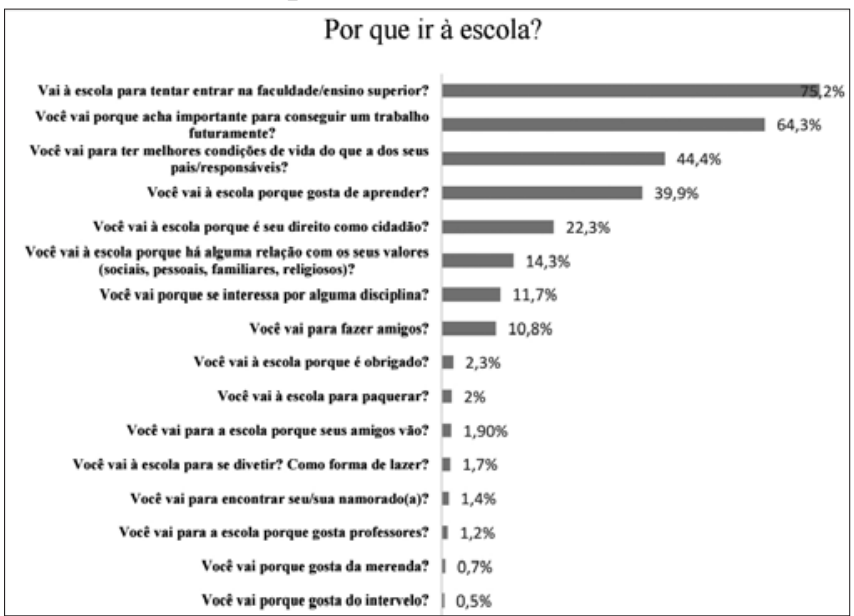


De maneira geral, podemos afirmar que o universo escolar configura-se, para muitos jovens, primeiro pela valorização do estudo como uma promessa futura de garantir a continuidade nos estudos pela entrada no Ensino Superior, ou melhores possibilidades para a disputa de um lugar no mercado de trabalho, ao mesmo tempo em que supre uma possível falta de sentido no cotidiano que vivenciam no presente, falta essa, porém, menos valorizada ou, na maioria das vezes, que não faz parte dos contextos escolares.

Temos que, desde a origem do Ensino Médio, apresentaram-se contradições que permanecem na atualidade. Conforme Nosella (2011), a dualidade escola secundária/superior para as elites e a primária/profissional para trabalhadores persiste, apesar de muitos esforços para superá-la.

A crise profunda pela qual a escola passa hoje é, também, [...] reflexo de sua incapacidade pedagógica de formular currículos e métodos que incorporem o trabalho produtivo sem renunciar à dimensão desinteressada e universal da cultura clássica (Nosella; Buffa, 2002). Porém, a partir dos dados, temos que, a despeito da construção e das proposições em torno da escolarização no Brasil se direcionarem nesse sentido dicotômico, a vontade e o interesse dos jovens não demonstram essa diferenciação, eles querem chegar ao Ensino Superior, tanto os jovens das escolas particulares quanto os da escola pública, apesar de as condições para que isso aconteça serem bastante desiguais. É uma situação de contradição entre o que a sociedade espera da escola e o que a escola tem sido capaz de oferecer a esses jovens.

Considerando a conquista histórica do acesso à escola enquanto direito, sua ampliação em todos os níveis e a universalização em processo, no caso aqui do Ensino Médio, as escolas, principalmente as públicas, passaram a receber um contingente de alunos cada vez mais heterogêneo, marcado por um contexto de desigualdade social e exclusão, então, o perfil do aluno tem mudado e as demandas trazidas para uma escolarização de qualidade são diferenciadas.

Segundo dados do IBGE (2015), o tempo de permanência na escola entre os mais pobres aumentou em $36 \%$ entre $2003^{8}$ e 2013 , sendo que para jovens com idades entre 16 e 17 anos e que alcançaram o mínimo de presença exigida, esse aumento foi de 75\% (IBGE, 2015).

Decorrente da recente expansão das oportunidades escolares, também no Ensino Médio no Brasil, enxerga-se uma nova reconfiguração da realidade da escola, que não acompanha a qualidade e modernidade do ensino, levantando novas questões e dilemas para a compreensão da experiência escolar, da concretização das necessidades e vontades dos jovens, de todos os segmentos sociais.

Muitas dessas questões encontram-se ainda por resolver, junto àquelas referidas à identidade e função do Ensino Médio, se propedêutico, técnico ou articulando essas duas dimensões. Como, afinal, a socie- 
dade brasileira se posiciona quanto às razões dessa etapa da educação e se é, ou não, um direito de todos a ser garantido com isonomia. Seria necessário que se refletisse acerca dessa fase final de uma educação tida como básica em nosso país, mas não fundamental, sobre sua relação com o mercado de trabalho, com o Ensino Superior e com a educação pensada em termos mais amplos, vinculada às noções de autonomia e cidadania, que contemple todos os jovens.

É importante frisar as discordâncias e contraposições quando se trata do Ensino Médio, pois estas atingem a própria definição do seu estatuto teórico-pedagógico, uma vez que uns defendem uma formação humanista e científica única para todos; outros, uma formação pré-profissional ou até mesmo profissionalizante; outros ainda defendem a separação entre o Ensino Médio regular e o ensino técnico e profissional; e outros, finalmente, defendem o Ensino Médio integrado ao ensino técnico ou à educação profissional (Nosella, 2011).

Saviani (1997) defende o pressuposto de que a educação hoje não pode mais conduzir-se somente como acadêmica ou profissionalizante, já que desse modo estaria formando um homem parcial e limitado, dado que a revolução técnico-científica supera as especializações convencionais, exigindo pessoas com aprofundada cultura geral e tecnológica, com capacidade para dominar processos produtivos complexos. Para atender a essa demanda, as escolas devem ser de um tipo único e assegurar os conhecimentos indispensáveis ao entendimento do homem em todas as suas dimensões.

Quando expusemos os resultados dos questionários para os jovens que participaram da conversa coletiva, algumas ponderações apareceram na direção de apontar uma perspectiva que vai além dessa dualidade e ainda não foram assimiladas pela escola, que tem como principal diretriz um projeto educacional no qual a emancipação humana deva ser primeiramente considerada.

[...] bom, hoje em dia, é claro, você vai ter que sobreviver, ninguém vai conseguir sem ter um trabalho no futuro, não vai poder, sei lá, praticar o ócio sem um trabalho, todo mundo vai ter que trabalhar e ganhar dinheiro, mas me incomoda serem esses três principais motivos para pessoas irem para escola, não ter nada para a vida da pessoa para ela querer aprender, descobrir (Luan).

Pode-se dizer que existe uma valorização da relação da escola com o futuro dos jovens que vem em paralelo ao fato de estudar para ter bons empregos e melhores condições financeiras, que está articulada a valores do consumo e da possibilidade de manter ou adquirir status na sociedade. Ao estabelecer uma relação um pouco mais aprofundada com esses atores do Ensino Médio, pode ser que os motivos que os levam a estar no espaço escolar sejam mais do que a busca pela qualificação para o trabalho ou inserção no Ensino Superior. A escola também é vista como um espaço de sociabilidade, de convivência, de diverti- 
mento e a possibilidade de aprender coisas novas, como uma forma de ressignificar e valorizar esse território de aprendizagens.

A escola ao se expandir em busca de sua universalização fomenta um espaço de intensificação e abertura das interações com o outro e, portanto, um caminho privilegiado para a ampliação da experiência de vida dos jovens. É inegável que os caminhos e contornos para entrada na vida adulta se diversificam, tornam-se mais complexos e menos lineares. Assim, o modo como os jovens vivem essa etapa de vida e sua relação com a escola se altera e oscila, uma vez que a escolaridade já não se afigura mais como elemento garantidor da continuidade dos estudos e mesmo da entrada no mundo do trabalho.

É fato que o papel da escola também é ensinar boas teorias, disponibilizando e formando para o acesso ao patrimônio cultural da humanidade; no entanto, para que funcione, é preciso que o aprendizado não seja apenas prático, mas seja intenso e, de verdade, o aluno domine com intimidade o que está sendo aprendido. O dilema é que, com vistas ao ingresso no Ensino Superior, o aluno é bombardeado por conteúdos que não se transformam em conhecimentos. Quer dizer, “[...] o ensino acadêmico para o mundo do vestibular é diferente do ensino, também acadêmico, para o mundo real. Somem-se a isso as diferenças de aptidão de cada aluno para as disciplinas mais acadêmicas e abstratas" (Castro, 2008, p. 116).

Os alunos, professores e pais vivenciam um cenário paradoxal, ou seja, lançam para o futuro o sentido do ensino no presente enquanto se encontram inseridos em uma sociedade cuja cultura é aquela que incentiva homens e mulheres a não planejar ou a esperar, mas a viver o aqui e agora das oportunidades de fruição prazerosa (Costa, 2004). Para Bauman (1998), a pós-modernidade significa um tempo de incertezas, ao lado de uma cultura em que as instituições sociais, como a escola, por exemplo, já não conseguem auxiliar o indivíduo satisfatoriamente na construção de suas identidades, bem como no planejamento de seus projetos de vida.

O esforço deveria estar em torno da reflexão dos atores escolares sobre a condição juvenil de seus alunos e as demandas que eles apresentam para a escola; como contribuir para a construção de seus projetos de futuro, articulando necessidades atuais e repensando a forma utilizada para responder aos desafios que as juventudes nos colocam.

Quando nos referimos à questão do aprendizado e ao sentido atribuído para essa prática, consideramos o aprendizado mais sistemático, apostilado, além da ideia de um currículo com conteúdos obrigatórios, fragmentados e divididos em conteúdos programáticos, com uma carga horária preestabelecida para todos e que são definidos, principalmente, com foco nos exames de vestibulares e/ou mais atualmente no ENEM $^{9}$ e, muitas vezes, desconsidera a realidade dos jovens estudantes.

Por outro lado, percebe-se uma disposição das pessoas em geral, e particularmente dos jovens, com vontade e interesse em aprender. 
Então eles buscam, procuram situações e fatos novos, com os quais se identifiquem e que façam sentido em suas vidas, julgando a cultura científica importante, mas não suficiente, sendo necessária sua articulação com o conhecimento de caráter popular e com os saberes que os jovens trazem para as salas.

Os jovens enfocam a questão da qualidade de ensino em relação a um conteúdo que englobe outros aportes e recursos didáticos que despertem seu interesse, indicam a importância de fazerem referência ao seu cotidiano, tomando-se produções e conhecimentos do jovem estudante, relacionando-se o conhecimento popular com o conhecimento científico da escola, a fim de estabelecer pontes e assim contribuir para o enriquecimento do processo de ensino-aprendizagem (Santos; Nascimento; Menezes, 2012). Na reflexão do aluno Luan:

Hoje em dia a gente vai para escola, escuta o sinal, senta em fileira, negócio burocrático, para aprender, decorar fórmula, para um dia passar no vestibular, é uma coisa que você aprende para o vestibular e não para sua vida. A escola perdeu totalmente o sentido dela, tanto que hoje ela virou exatamente o que nega o ócio, virou negócio, virou totalmente ao contrário. Assim, quando pergunta para um professor, "aonde isso vai se encaixar na minha vida?”, pode ser uma superequação, você não vai usar aquela superequação para atravessar o sinal na rua, não, você não vai usar aquilo na sua vida, só que a escola não ensina mais o prazer da descoberta, você querer aprender, a escola na verdade faz você perder isso quando entra lá (Luan).

Para os jovens que participaram da conversa coletiva, existe certo distanciamento de seus interesses com o que a escola oferece. Eles anseiam e se interessam por aprender e continuar aprendendo continuamente, tendo em vista o prazer da descoberta do outro, de si mesmo e do mundo.

Os jovens alunos visualizam a importância e consideram como principais sentidos da ida à escola a entrada na universidade e a conquista de um bom trabalho. Assim, depositam essas vontades e demandas na escola para a realização desses projetos futuros, mas também criam sentidos e significados para irem à escola diariamente, um deles é o interesse em aprender não apenas conteúdos sistematizados e científicos.

Eu acho que o que deveria ser a alma do negócio é que está só vendo o final do processo que é o entrar em uma faculdade e ter um curso superior, não vê o decorrer que é aprender mesmo, o saber, ter o conhecimento. Se você perguntar para uma criança da quinta série o sentido da escola, ela vai falar que é entrar em uma faculdade [...] eu acho que é errado, eu acho que desde sempre é colocado na nossa cabeça que a gente tem que ir à escola para passar na faculdade e depois ir trabalhar num lugar legal, mas não é só isso. A gente tem que ir à escola para aprender, para saber da nossa história, para saber por que as coisas são como são, porque a sociedade funciona desse jeito (Janaína). 
A escola é vista como uma instituição única e importante, com os mesmos sentidos e objetivos, tendo como função garantir a todos o acesso ao conjunto do conhecimento socialmente acumulados pela sociedade, sendo que esses conhecimentos, porém, são reduzidos a resultados e conclusões, sem se levar em conta o valor determinante dos processos vivenciados pelos alunos (Dayrell, 1996).

Para Dayrell (1996), o conhecimento escolar se torna objeto, coi$s a$, quando materializado nos programas e livros didáticos a ser transmitido, o ensinar se torna transmitir esse conhecimento acumulado e aprender se torna assimilá-lo. A ênfase dada está centrada nos resultados que a aprendizagem proporciona, sendo valorizadas as notas e as provas; assim, a finalidade da escola se reduz ao passar de ano. Nessa lógica, não há razão para aliar o vivenciado pelos alunos ao conhecimento escolar, a escola ao extraescolar, justificando-se a desarticulação existente entre o conhecimento escolar e a vida deles.

Dessa forma, no processo de ensino-aprendizagem, ocorre uma homogeneidade de ritmos, estratégias e propostas educativas para todos, independentemente da origem social, da idade e das experiências vividas. A diversidade real dos alunos é reduzida a diferenças apreendidas na ótica da cognição (bom ou mau aluno, esforçado e preguiçoso) ou na do comportamento (bom ou mau aluno, obediente ou rebelde, disciplinado ou indisciplinado). Essa prática escolar desconsidera a totalidade das dimensões humanas dos sujeitos - alunos, professores, funcionários - que dela participam (Dayrell, 1996).

\begin{abstract}
Hoje, a escola não está em sua função ativa na perspectiva anunciada, muito menos naquela em que se pauta pela emancipação humana. Há produção de sentidos, porém com conteúdos distantes de uma formação que realmente desenvolva as capacidades humanizadoras dos sujeitos históricos, que os torne capazes de desenvolver uma percepção adequada do meio a sua volta e de, conscientemente, nele agir para transformá-lo e, com isso, transformar-se (Mendonça, 2011, p. 352).
\end{abstract}

[...] se for uma pessoa que aprendeu coisas legais, ideias legais, que tem um conhecimento grande sobres as coisas, acaba ganhando conhecimento grande sobre a vida, consegue falar de muitas coisas, consegue ter ideias de muitas coisas, pensar em muitas coisas. Acho que o entrar na faculdade e ter um bom emprego é só uma consequência que vem quase de graça se você tiver um bom conhecimento, uma bagagem (Janaína).

Percebemos que os jovens alunos não fazem, pelo distanciamento, a ponte do conhecimento que adquirem no dia a dia com o conhecimento conduzido na escola. Há certa dicotomia entre o mundo significativo do estudante e o processo de ensino-aprendizagem na escola. Como a escola parece ignorar que a construção do saber passa pela relação da educação com a vida, o estudante perde a visão da sua construção social e cultural (Navarro, 2005). 
Eu acho que eles podiam bolar um conteúdo menos mecânico, um conteúdo, tipo, que focasse mais na gente mesmo, mais no que nos cerca, mais daquilo que é importante para gente, para a gente aprender e conseguir viver bem depois, uma vida razoável enquanto pessoa, não enquanto indivíduo financeiramente, mas como pessoa mesmo, para a gente aprender mais da questão do que aconteceu para a gente chegar até aqui, do mundo que nos cerca (Alana).

É importante compreender que os jovens estudantes pedem uma escola que estabeleça uma ligação entre a razão e a realidade, capaz de refletir sobre o significado do conhecimento e a forma como ele está sendo assimilado pelos estudantes, com captação do conteúdo da vida real e criando relações novas no espaço da escola, motivando o estudante para concepções emancipatórias sobre o mundo, o trabalho, as relações sociais, enfim, sobre a vida.

Os jovens têm objetivos quanto ao seu futuro, o trabalho ou a entrada no Ensino Superior. Consequentemente, associam a realização destes com a escola e seu processo dentro dela. Porém, criam significados importantes para irem e permanecerem nessa instituição e, assim, chegarem ao seu objetivo final. Conferem sentidos positivos ao ato de aprender, com isso podemos considerar que visualizam no Ensino Superior a continuidade dos estudos e valorizam nesse nível de ensino a possibilidade de aprenderem coisas novas, pois não demonstram interesse com relação às disciplinas curriculares e aos conteúdos mais sistemáticos do Ensino Médio, criticam a forma como são reproduzidos no modelo da escola em que estão:

Passar no vestibular é a questão geral, é a minha também, mas não é em primeiro lugar, eu vou porque eu quero aprender realmente, mas que muitas vezes eu acabo não aprendendo, eu vou porque eu quero aprender uma coisa nova, uma coisa diferente, mas aí você vê que tem muito professor que está alienado naquele conteúdo, naquela coisa assim, ele chega, faz o trabalho dele e vai embora, ele não está interessado em ensinar e passar coisas novas e aí você acaba se preocupando mais com o resto mesmo, 'como eu vou fazer para passar no vestibular agora e tal', eu acho que em primeiro lugar para mim seria buscar novos conhecimentos e em segundo passar no vestibular. Acho que como meu objetivo é aprender coisas novas a escola fica um pouco a desejar nessa parte e o dia se torna maçante, eu acabo extravasando às vezes batendo papo com o pessoal, mas a parte que seria interessante mesmo, pelo que eu acordo cedo e vou para lá não recebo de volta (Alana).

Além da busca pelo trabalho a partir do Ensino Superior, há a busca por melhores condições de vida, um lugar para aprender, como vimos anteriormente, e a escola como possibilidades de contatos sociais, de divertimento e de convívio. Podemos pensar nessa sociabilidade, pois sabemos da importância do grupo de amigos para os jovens, o valor das turmas com suas particularidades, por criarem seus próprios códigos e rituais. Eles interagem, criam redes, teias de socialização, e buscam firmar identidade e demarcar território (Menezes; Arcoverde; Liberdi, 2008).

208 Educação \& Realidade, Porto Alegre, v. 41, n. 1, p. 193-216, jan./mar. 2016. 
Ao analisar os dados reunidos com o questionário, podemos aventar algumas hipóteses das razões para que os jovens não considerem, ou considerem pouco, a escola como um espaço aonde vão para exercer algum tipo de socialização, para além da imposição social de que a escola no terceiro ano do Ensino Médio não deve ter essa característica, dada a importância do que pode significar em termos de objetivos colocados para o futuro.

Talvez os jovens, ao responderem o questionário, tenham reproduzido o que a sociedade cria de sentidos e expectativas para a escola, em relação à conduta dos jovens do último ano da Educação Básica, por isso não tenham lançado mão de alternativas a essa suposição, não dando importância sobre o sentido que eles realmente atribuiriam a essa instituição. Por fim, podem ter respondido de maneira a refletir o que julgam ser a resposta esperada pela sociedade e pela escola.

Outra hipótese é a de que a própria escola não percebe a sua importância como espaço de sociabilidade, e isso não seja objeto de sua ação. Ao não explorar os espaços escolares, os estudantes ficam restritos à sala de aula, e sua circulação no espaço da escola se transforma em objeto de controle. Segundo Carrano e Peregrino:

\begin{abstract}
No espaço já fragmentado da escola, a circulação deve ser reduzida. As idas ao banheiro, confinadas aos tempos exíguos dos intervalos; o recreio em espaços definidos; as entradas e saídas de alunos observados. As escolas, assim constituídas, se configuram como espaços de contenção física e simbólica de jovens (Carrano; Peregrino, 2003, p. 20).
\end{abstract}

Porém, marcados por um cotidiano denso, os jovens transformam o ambiente da escola em espaços agradáveis, onde há lugar para o namoro, encontro com os amigos e conversas, recriando esses espaços nos interstícios da organização escolar, entre uma aula e outra, nas ausências dos professores; contudo, não consideram essas relações como sentidos que atribuem ao fato de irem à escola, mas acabam aproveitado e se beneficiando dessas oportunidades. A questão é como a própria escola interage com esses acontecimentos, admitindo-os como importantes e necessários ao processo de formação; a turma de amigos ou a falta dela é uma referência na trajetória dos jovens.

Enfim, podemos afirmar que a sociabilidade, para os jovens, parece responder às suas necessidades de comunicação, de solidariedade, de democracia, de autonomia, de trocas afetivas e, principalmente, de identidade (Dayrell, 2007). Seja isso consciente ou não, a equipe escolar precisaria incorporar tal aspecto, potencializando e valorizando esses processos.

Como já visto pelos estudiosos e teóricos, a expectativa em torno da escola é muito mais ampla; seu desenho retrata uma instituição verdadeiramente polivalente, capaz, em tese, de ocupar uma série de diferentes espaços no contexto social, seja no suprimento, seja no oferecimento de oportunidades para que esses jovens alcancem seus objetivos 
(Esteves, 2005). Porém, não é essa perspectiva, de forma imediata, que trazem os jovens, como vimos, por meio dos dados dos questionários e da conversa coletiva.

Refletir sobre o papel social da escola a partir da ótica das juventudes é, sem dúvida, uma tarefa difícil, visto que abarca, dentre outras características, desde noções socialmente construídas e confirmadas ao longo da história até outras que encontram um melhor significado no campo dos desejos individuais, implicando diretamente, portanto, a observação ou o atendimento de anseios específicos.

Assim, não se trata mais de manter a escola como um local apenas do conhecimento, isto é, no domínio dos conteúdos, mas de idealizar e oferecer uma escola que valorizará formas de organização nas quais prevaleçam a integração social, a convivência entre diferentes, o compartilhamento de culturas, o encontro, a solidariedade entre as pessoas e sua formação, além de um ensino que possibilite a todos se apropriarem dos conhecimentos produzidos ao longo da história, de modo que cada indivíduo em particular possa objetivar-se enquanto um ser humano pleno, histórico e social (Moura, 2013).

Com a especificidade e segregação da escola, percebemos que as competências gerais acabam se realizando em um campo profissional específico, de maneira que parece que não se mistura a discussão entre formação geral e formação técnica, sendo imprescindível destacar a necessidade de um equilíbrio entre as duas formações, visto que o jovem deve ser preparado durante a escolarização básica para assumir os múltiplos papéis que o esperam, pois, ao mesmo tempo em que é estudante, é também, filho, irmão, cidadão etc. (Krawczyk, 2011).

Convivendo com um monte de gente que tem criação diferente da sua e que vai ser na sua vida, em um emprego vai conviver com pessoas que são diferentes de você, que pensam diferente de você, então seus pais não vão estar lá, acho que a escola é uma prévia do que a gente vai viver em sociedade sim, aí fica meio tenso se a gente acha que é um tédio ir para a escola o que vai ser a vida então né? (Alana).

Cabe à escola formar cidadãos críticos, reflexivos, autônomos, conscientes de seus deveres e direitos, capazes de compreender a realidade em que vivem, preparados para participar da vida econômica, social, cultural e política do país. Porém, a materialização dessa concepção educacional enfrenta uma disputa política direta com o capital, “[...] uma vez que esse tipo de formação claramente não lhe interessa, e sim, a formação estrita para o atendimento imediato aos interesses do mercado de trabalho" (Moura, 2013, p. 717).

Se eu tivesse que propor uma mudança social, a educação seria basicamente a chave, mas a escola de hoje eu acredito que ela não cria indivíduos críticos, por exemplo, a própria situação é muito mais você passar pela escola e conseguir um emprego no futuro do que você questionar sua posição social, também isso não seria interessante para quem comanda formar 'revolucionariozinhos' na escola, pessoas autocríticas e eu acre- 
dito que a escola segue bem esse modelo, ela não cria indivíduos críticos ela simplesmente deixa o indivíduo na posição social que está, não cria cientistas, não cria artistas, na verdade tem uma banalização com essa parte, filósofos muito menos (Luan).

\section{Considerações Finais}

Para que se avance na direção da concretização da concepção ampla de formação e, enfim, romper a dualidade estrutural estabelecida na educação escolar, não se depende apenas do sistema educacional, mas, antes, da transformação do modo de produção vigente, compreendendo que essa dualidade histórica não nasce na escola, é fruto da sociedade dual/cindida em que vivemos.

É muito importante ressaltar que isso não significa que a educação deva esperar que ocorra primeiramente a superação ou a mudança do atual modo de produção para depois construir uma escola única. Conforme Gramsci (2008), a proposta de uma escola única está relacionada à compreensão de uma educação preocupada com a emancipação humana, ou seja, com o desenvolvimento da autonomia intelectual e cultural dos sujeitos.

Os jovens consideram a escola um suporte para enfrentar os embates e obstáculos e nela depositam confiança, expectativas, sonhos e esperanças com relação à execução de seus projetos de vida. Apesar de todas as dificuldades que vivenciam nesse contexto, veem a escola como um instrumento importante para tornar realidade seus projetos, fazendo com que nela permaneçam.

Portanto, os jovens compõem sentidos positivos e se motivam em relação à escola, não obstante, sabem apontar as deficiências e fragilidades nela presentes sem, com isso, desvalorizá-la.

Com uma expectativa mais ampla em torno da escola, retratando uma instituição verdadeiramente da cultura humana, os jovens têm como principal sentido para estarem e permanecerem na escola aquilo que a educação burguesa imprimiu às sociedades industriais desde o século XIX, uma melhor configuração para o trabalho, algo necessário para manter a expectativa/possibilidade de um bom emprego, seja ou não por meio do acesso ao Ensino Superior.

A sociedade precisa transmitir suas tradições e alicerces construídos no decorrer da história. As metodologias para que isso aconteça envolvem uma longa e árdua discussão, porém, entendendo a educação como um direito e um dever, os jovens têm direito e o dever de receberem o que a humanidade construiu, de serem preparados para a vida em sociedade, para o exercício da cidadania, para uma vida prática contextualizada e também para o trabalho, mas, para isso, é preciso que se reverta uma direção histórica, que, no Brasil, se deu e continua se dando, ao luxo de não preparar devidamente a maioria daqueles que serão o futuro. 
Foi importante compreender que, a despeito das dificuldades amplamente mencionadas como obstáculos ao ato de estudar para os jovens e do fato de gostarem ou não da escola que lhes tem sido ofertada, eles criam e estabelecem sentidos para a presença nessa instituição, onde vivenciam experiências importantes e necessárias para uma construção de significados em longo e em curto prazo.

Há a necessidade de entender os processos escolares, potencializar aqueles que permanecem e dão continuidade aos estudos e contribuir para reforçar as possibilidades da escola, como um local importante de sociabilidade, que pode proporcionar experiências formadoras de ação coletiva e facilitar um espaço de troca. Trata-se de um equipamento social que compõe uma rede de serviços, principalmente para jovens de grupos populares, e deve integrar uma rede de suporte que, dentre outros bens sociais, amplie o sentido da educação para o jovem. Uma escola que tenha como proposição a formação humana plena, facilitando as situações educacionais mais práticas pela transmissão de saberes e conhecimentos úteis ao dia a dia dos jovens, uma escola que construa a articulação da educação com vivências para a atuação na sociedade, em um espaço que seja protegido, física e emocionalmente, para que todas as potencialidades dos jovens aflorem e não feneçam.

$\mathrm{Ou}$, em outras palavras, naquelas de um dos maiores pensadores contemporâneos acerca dos sentidos da educação:

\begin{abstract}
[...] diante das exigências do mundo moderno, nós precisamos mirar o mais possível na preparação do aluno não somente para ser ele mesmo, mas também para entrar na sociedade, senão com a capacidade de ser um produtor de cultura em todos os campos, pelo menos para ter a capacidade de desfrutar, de saber gozar, de todas as contribuições da civilização, das artes, das técnicas, da literatura. A cultura deve ser direcionada para todos, facilitando as disposições intelectuais e ao mesmo tempo forçando todo mundo, com firme doçura a aprender e a participar de todos os prazeres humanos (Manacorda apud Nosella; Lombardi; Saviani, 2007, p. 23).
\end{abstract}

Ensinar e aprender para viver e viver junto, para a radicalização da democracia, para a capacidade de movimento e de tensionamento do que está posto.

Recebido em 30 de maio de 2015 Aprovado em 17 de novembro de 2015

\title{
Notas
}

1 Citamos aqui Karl Mannheim e seu empenho na discussão sociológica de geração e juventude, nos textos "O problema da juventude na sociedade moderna" (Mannhein, 1968) e "O problema sociológico das gerações" (Mannhein, 1982), dentre outros; Pierre Bourdieu e sua argumentação em "A juventude é apenas uma palavra” (Bourdieu, 1983), com a qual dialogam Mario Margulis e Marcelo Uresti, oferecendo um importante contraponto em seu texto "A juventude é mais que uma palavra" (Margulis; Urresti, 1996). 
2 De acordo com o Estatuto da Juventude, no Brasil, são consideradas jovens as pessoas com idade entre 15 e 29 anos de idade (Brasil, 2013).

3 Uma das discussões acerca da "juventude" recai sobre sua faixa etária, questionando-se os marcos delimitadores inicial e final dessa fase, os ritos de passagem da infância para a adolescência e juventude e, posteriormente, o demarcador de entrada na vida adulta. A Organização Mundial de Saúde (OMS) classifica como jovens aqueles com idade entre 15 e 24 anos. No Brasil, apesar do Estatuto da Juventude aprovado em 2013, permanece o debate em torno dos limiares entre 15 e 29 anos, faixa que compreende parte do que hoje também se denomina adolescência, a qual, por outro lado, tem uma definição legal que vai dos 12 anos completos aos 18 anos incompletos. A discussão de sua delimitação superior, nos termos do que se demarca como maioridade penal, é uma questão que se reacendeu entre nós na atual legislatura.

4 À guisa de exemplos: "Você vai para escola porque é obrigado?", "Você vai porque se interessa por alguma disciplina?", "Você vai para fazer amigos?", "Vai à escola para tentar entrar na faculdade/ensino superior?", dentre outras, nas quais os jovens poderiam assinalar "Sim" ou "Não" para cada alternativa. Havia também a possibilidade do respondente, na opção "Outro", completar com uma formulação própria.

5 Por diferentes motivos, efetivamente, no período da pesquisa participaram cinco estudantes.

6 Se tomarmos como referência a faixa etária da adolescência (12-18 anos) definida pelo Estatuto da Criança e do Adolescente (Brasil, 1990), aqui poderíamos utilizar essa terminologia para nos referirmos aos sujeitos da pesquisa, porém optamos pelo termo "jovem”, já que a concepção de adolescência muitas vezes se caracteriza apenas por transformações biológicas, que transcendem às esferas psicológica e social em direção à maturidade biopsicossocial (Peres; Rosenburg, 1998).

7 Cada aluno relacionou, em ordem decrescente, três itens que considerou como mais importantes, dentre as possibilidades colocadas pelo instrumento. Desse modo, os percentuais representados na Figura 2 não somam $100 \%$. O percentual para cada item é referente aos alunos que o escolheram como mais importante. Assim, 75,2\% dos alunos afirmaram que o item mais importante é "ir para escola para tentar entrar na faculdade". O segundo mais importante $(64,3 \%)$ foi o item "vai para a escola porque acha importante para conseguir um trabalho futuramente" e o terceiro $(44,4 \%)$ foi o item "vai para a escola para ter melhores condições de vida do que a dos seus pais/responsáveis".

8 O Programa Bolsa Família (PBF), criado em 2003, no âmbito das políticas de assistência social no Brasil, é fruto do processo de unificação de diferentes programas de transferência de renda para a população mais pobre. De forma geral, tem como objetivos combater a fome, a pobreza e outras formas de privação das famílias, promover a segurança alimentar e nutricional e o acesso à rede de serviços públicos de saúde, educação e assistência social. Estudos realizados apontam para a significativa melhora na qualidade de vida dos beneficiários do PBF, nos setores da alimentação, educação e saúde. Na educação, ocorre a permanência e progressão de crianças, adolescentes e jovens oriundos de famílias beneficiárias nas escolas, no entanto os atores envolvidos insistem que o PBF, embora tenha impactado a frequência, não melhorou de forma efetiva a questão do aproveitamento escolar (Bichir, 2010; Pires, 2013).

9 Exame Nacional do Ensino Médio. 


\section{Referências}

ABRAMO, Helena Wendel. Considerações sobre a tematização social da juventude no Brasil. Revista Brasileira de Educação, Rio de Janeiro, n. 5, p. 25-36, maio/ago. 1997.

BAUMAN, Zygmunt. Modernidade Líquida. Rio de Janeiro: Zahar, 2001.

BAUMAN, Zygmunt. O Mal-Estar da Pós-Modernidade. Rio de Janeiro: Zahar, 1998. BICHIR, Renata Mirandola. O Bolsa Família na Berlinda? os desafios atuais dos programas de transferência de renda. Novos estudos - CEBRAP, São Paulo, n. 87, p. 115-129, 2010. Disponível em: <http://dx.doi.org/10.1590/S010133002010000200007>. Acesso em: 25 maio 2015.

BOURDIEU, Pierre. A juventude é Apenas Uma Palavra. In: BOURDIEU, Pierre. Questões de Sociologia. Rio de Janeiro: Marco Zero, 1983. P. 112-121.

BRASIL. Estatuto da Criança e do Adolescente. Lei n.o 8069. Imprensa Oficial do Estado, São Paulo, 1990.

BRASIL. Ministério da Educação. Lei n. ${ }^{0} 12.852,5$ de agosto de 2013. Diário Oficial da União, Brasília, 2013. Disponível em: <http://www.planalto.gov.br/ccivil_03/_Ato2011-2014/2013/Lei/L12852.htm>. Acesso em: 20 fev. 2013.

BRASIL. Ministério da Educação. Disponível em: <http://portal.mec.gov.br/index.php?option=com_content\&id=12583:ensino-medio\&Itemid=859>. Acesso em: 13 fev. 2015.

CARRANO, Paulo; PEREGRINO, Mônica. Jovens e Escola: compartilhando territórios e sentidos de presença. In: NASCIMENTO, Iracema. A Escola e o Mundo Juvenil: experiências e reflexões. São Paulo: Ação Educativa, 2003. P. 12-21.

CASTRO, Cláudio de Moura. O Ensino Médio: órfão de ideias, herdeiro de equívocos. Ensaio: avaliação e políticas públicas em educação, Rio de Janeiro, v. 16, n. 58, p. 113-124, 2008.

CHARLOT, Bernard. Da Relação com o Saber: elementos para uma teoria. Porto Alegre: Artmed, 2000.

COSTA, Jurandir Freire. Perspectivas da Juventude na Sociedade de Mercado. In: NOVAES, Regina; VANUCCHI, Paulo. Juventude e Sociedade - trabalho, educação, cultura e participação. Rio de Janeiro: Perseu Abramo, 2004.

DAYRELL, Juarez. A Escola "faz" as Juventudes? Reflexões em torno da socialização juvenil. Educação e Sociedade, Campinas, v. 28, n. 100, p. 1105-1128, 2007. DAYRELL, Juarez. O Jovem Como Sujeito Social. Revista Brasileira de Educação, Rio de Janeiro, n. 24, p. 40-52, 2003.

DAYRELL, Juarez. Múltiplos Olhares Sobre Educação e Cultura. Belo Horizonte: Editora UFMG, 1996.

ESTEVES, Luis Carlos Gil. Estar no Papel: cartas dos jovens do ensino médio. Brasília: UNESCO; INEP/MEC, 2005.

FRIGOTTO, Gaudêncio. A Produtividade da Escola Improdutiva: um (re)exame das relações entre educação e estrutura econômico-social e capitalista. 3. ed. São Carlos: Cortez; Autores Associados, 1989.

GRAMSCI, Antônio. Excerto do Caderno 12: para a história dos intelectuais. In: NOSELLA, Paolo. Antonio Gramsci para os Educadores: antologia organizada por Paolo Nosella. São Paulo: UNINOVE/UFSCar, 2008. P. 74-95.

INSTITUTO BRASILEIRO DE GEOGRAFIA E ESTATÍSTICA - IBGE. Cidades. São Carlos. 2013. Disponível em: <http://www.ibge.gov.br/cidadesat/topwindow. htm>. Acesso em: 11 dez. 2013

214 Educação \& Realidade, Porto Alegre, v. 41, n. 1, p. 193-216, jan./mar. 2016 
INSTITUTO BRASILEIRO DE GEOGRAFIA E ESTATÍSTICA - IBGE. Educação. 2015. Disponível em: <http://www.ibge.gov.br/home/estatistica/populacao/ condicaodevida/indicadoresminimos/suppme/default_educacao.shtm $>$. Acesso em: 11 nov. 2015.

IULIANELLI, Jorge Atílio Silva. Juventude: construindo processos: o protagonismo juvenil. In: FRAGA Paulo César Pontes; IULIANELLI, Jorge Atílio Silva (Org.). Jovens em Tempo Real. Rio de Janeiro: DP\&A, 2003. P. 19-37.

KRAWCZYK, Nora. Reflexão sobrealguns desafios do ensino médio no Brasilhoje. Cadernos de Pesquisa, São Paulo, v. 41, n. 144, p. 752-769, 2011.

KUENZER, Acácia Zeneida. Ensino Médio e Profissional: as políticas do estado neoliberal. 4. ed. São Paulo: Cortez, 2007.

KUENZER, Acácia Zeneida. Exclusão includente e inclusão excludente: a nova forma de dualidade estrutural que objetiva as novas relações entre educação e trabalho. In: SAVIANI, Demerval; SANFELICE, José Luis; LOMBARDI, José Claudinei (Org.). Capitalismo, Trabalho e Educação. 3. ed. Campinas: Autores Associados, 2005. P. 77-96.

LOPES, Roseli Esquerdo; SILVA, Carla Regina; MOURA, Beatriz Rocha; OISHI, Jorge. Adolescentes e Jovens em Escolas Públicas de Ensino Médio em São Carlos/SP: perfil socioeconômico e a questão da violência. In: FERREIRA, Amarílio; MASSAO, Carlos Roberto H.; LOMBARDI, José C. (Org.). A Educação Brasileira no Século XX e as Perspectivas para o Século XXI. Campinas: Alínea, 2012. P. 201-234.

LOPES, Roseli Esquerdo; BORBA, Patrícia Leme de Oliveira; TRAJBER, Natália Keller; SILVA, Carla Regina; CUEL, Brena Talita. Oficinas de Atividades com Jovens da Escola Pública: tecnologias sociais entre educação e terapia ocupacional. Interface, Botucatu, v. 15, p. 277-288, 2011.

LOPES, Roseli Esquerdo; ADORNO, Rubens de Camargo Ferreira; MALFITANO, Ana Paula Serrata; TAKEITI, Beatriz Akemi; SILVA, Carla Regina; BORBA, Patrícia Leme de Oliveira. Juventude pobre, violência e cidadania. Saúde e Sociedade, São Paulo, v. 17, n. 3, p. 63-76, 2008.

MAGALHÃES, Marcos Nascimento; LIMA, Carlos Pedroso. Noções de Probabilidade e Estatística. 2. ed. São Paulo: IME-USP, 2000.

MANNHEIM, Karl. O Problema Sociológico das Gerações. In: FORACCHI, Marialice Mencarini (Org.). Mannheim. São Paulo: Ática, 1982. P. 67-95.

MANNHEIM, Karl. O Problema da Juventude na Sociedade Moderna. In: BRITTO, Sulamita (Org.). Sociologia da Juventude I - da Europa de Marx à América Latina de hoje. Rio de Janeiro: Zahar, 1968. P. 69-94.

MARGULIS, Mario; URRESTI, Marcelo. La Juventud es más que una Palabra. In: MARGULIS, Mario (Org.). La Juventud es más que una Palabra: ensayos sobre cultura y juventud. Buenos Aires: Biblos, 1996. P. 13-30.

MENDONCA, Sueli Guadelupe de Lima. A Crise de Sentidos e Significados na Escola: a contribuição do olhar sociológico. Cadernos CEDES, Campinas, v. 31, n. 85, p. 341-357, 2011.

MENEZES, Jaileila Araújo; ARCOVERDE, Lilian Rocha; LIBERDI, Suzana Santos. A Pesquisa-Intervenção com Adolescentes: oficina como contexto narrativo sobre igualdade e diferença. In: CASTRO, Lucia Rabello de; BESSET, Vera Lopes (Org.). Pesquisa Intervenção na Infância e Juventude. Rio de Janeiro: Trarepa/ Faperj, 2008. P. 205-223.

MOURA, Dante Henrique. Ensino Médio Integrado: subsunção aos interesses do capital ou travessia para a formação humana integral? Educação e Pesquisa, São Paulo, v. 39, n. 3, p. 705-720, 2013. 
NAVARRO, Karina de Mota. O Significado da Escola para o Jovem Estudante do Ensino Médio Noturno. 2005. 109f. Dissertação (Mestrado em Educação) - Universidade Federal Fluminense, Niterói, 2005.

NOSELLA, Paolo. Ensino Médio: em busca do princípio pedagógico. Educação e Sociedade, Campinas, v. 32, n. 117, p. 1051-1066, 2011.

NOSELLA, Paolo; LOMBARDI, José Claudinei; SAVIANI, Demerval (Org.). Mario Aligheiro Manacorda: aos educadores brasileiros. Campinas: Unicamp/HISTEDBR-FE/CNPq, 2007. P. 1-26.

NOSELLA, Paolo; BUFFA, Ester. Schola Mater: a antiga Escola Normal de São Carlos, 1911- 1933. São Carlos: EdUSFCar, 2002.

PAIS, José Machado. Ganchos, Cachos e Biscates: jovens, trabalho e futuro. Lisboa: AMBAR, 2005

PAIS, José Machado. Juventude como Fase de Vida: dos ritos de passagem aos ritos de impasse. Saúde e Sociedade, São Paulo, v. 18, n. 3, p. 371-381, 2009.

PERES, Fumika; ROSENBURG, Cornélio. Desvelando a Concepção de Adolescência/ adolescente presente no discurso de saúde pública. Saúde e Sociedade, São Paulo, v. 7, n. 1, p. 53-86, 1998.

PIRES, André. Afinal, para que servem as condicionalidades em educação do Programa Bolsa Família?. Ensaio: avaliação e políticas públicas em educação, Rio de Janeiro, v. 21, n. 80, p. 513-531, 2013. Disponível em: <http://dx.doi. org/10.1590/S0104-40362013000300007>. Acesso em: 20 maio 2015.

SANTOS, Rubenize Maria dos; NASCIMENTO, Maria Aparecida; MENEZES, Jaileila de Araújo. Os sentidos da escola pública para jovens pobres da cidade do Recife. Revista Latinoamericana de Ciencias Sociales, Niñez y Juventud, Colombia, v. 10, n. 1, p. 289-300, 2012.

SAVIANI, Demerval. A Nova LDB da Educação: trajetória, limites e perspectivas. São Paulo: Autores Associados, 1997.

SCHWERTNER, Suzana Feldens; FISCHER, Rosa Maria Bueno. Juventudes, conectividades múltiplas e novas temporalidades. Educação em Revista, Belo Horizonte, v. 28, n. 01, p. 395-420, 2012.

SENNETT, Richard. A Corrosão do Caráter: as consequências pessoais do trabalho no novo capitalismo. 14. ed. Rio de Janeiro: Record, 2009.

Beatriz Prado Pereira é doutoranda em Educação no Programa de Pós- Graduação em Educação da Universidade Federal de São Carlos (UFSCar). Professora Assistente do Departamento de Terapia Ocupacional da Universidade Federal da Paraíba (UFPb).

E-mail: beatriz.pradop@gmail.com

Roseli Esquerdo Lopes é doutora em Educação pela Universidade Estadual de Campinas, com pós-doutorado em Saúde Pública. Professora Titular do Departamento de Terapia Ocupacional da Universidade Federal de São Carlos.

E-mail: relopes@ufscar.br 